\title{
Comparison of pure metal coating preparation by thermal spraying, cold spraying and electroplating methods
}

\author{
Di JIANG ${ }^{1}$, Nannan $Z \mathrm{ZHANG}^{1 *}$, Baozeng $\mathrm{LI}^{2}$, Yingjie $\mathrm{ZHANG}^{3}$, Deyuan $\mathrm{LI}^{1}$ \\ ${ }^{1}$ Shenyang University of Technology, Shenyang, CHINA \\ 2 Pinggao Group Co. Ltd., pingdingshan 467001, Henan, China \\ ${ }^{3}$ Henan Pinggao Electric Co. Ltd., pingdingshan 467001, Henan, China \\ Corresponding author : znn_sut@163.com
}

Keywords: thermal spraying; cold spraying; electroplate; aluminum alloy

Abstract. By using different kinds of deposit methods, such as thermal spraying, cold spraying and plating method, pure copper coating was prepared on aluminum alloy matrix. The preparation method, appearance of the copper coating, microstructure, and phase structure were then discussed.

\section{Introduction}

Electric Arc Spray Process ( Twin Wire Arc Spray process) is one of the thermal spraying methods. Two wires of desired materials act as electrodes when they're fed through a spray gun ${ }^{[1]}$. The arc temperatures can reach $5000^{\circ} \mathrm{C}$, enough to melt any metal material, at the same time the part surface remains cool ${ }^{[2]}$. High-speed cold spraying is compressed air loading solid particle impact the substrate and forms dense coating. The supersonic gas jet is not absolutely cold, the gas temperature is between $500^{\circ} \mathrm{C}$ and $600^{\circ} \mathrm{C}$ so as to make the particles carry more energy and strengthen the adherence with the substrate ${ }^{[3-5]}$. In this study, copper coating on the high-voltage switch was deposited on aluminum alloy substrate by arc spraying, cold spraying and plating so as to make the switch more lightweight.

\section{Experimental procedure}

The substrate material of this experiment was 6063 aluminum alloy. The spraying material was 99.97\% pure copper. The aluminum alloy plates were cut to size $50 \mathrm{~mm} \times 50 \mathrm{~mm} \times 4 \mathrm{~mm}$ samples, which were cleaned with acetone and sand blasting. This is because aluminium alloy is easy to react with oxygen in the air to form dense alumina which decreases bonding strength.

Fig. 1 shows $\mathrm{Cu}$ coating deposited by arc spraying method with different gas protection. The spraying specimen with compressed air color was darker because it was more easy oxidation than using nitrogen or argon protection. 


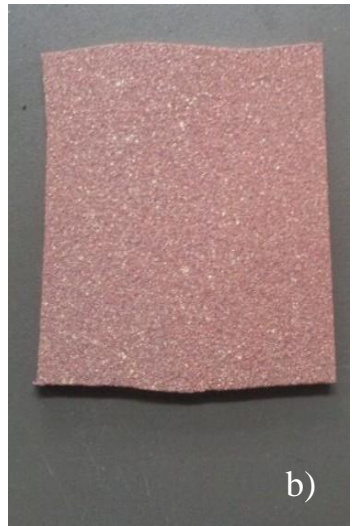

a) With air

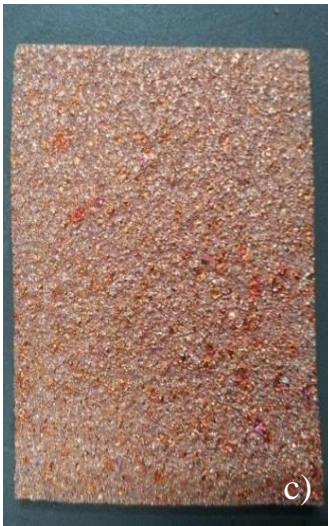

b) With Nitrogen

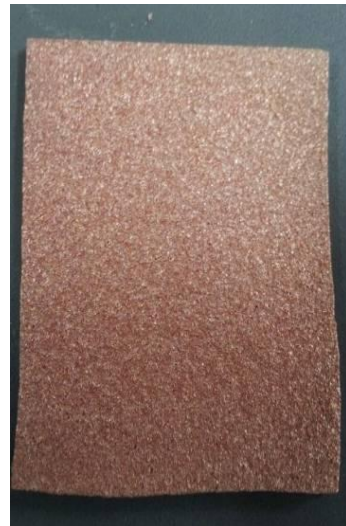

c) With Argon

Fig. $1 \mathrm{Cu}$ coating deposited by arc spraying method with different gas protection

\section{Results and discussion}

\section{Thermal spraying coating}

The performance of the arc spraying coating is decided by the coating quality which depends on the spraying equipment, materials, technology and other factors.

Fig. 2 shows the morphology of $\mathrm{Cu}$ coating by using arc spraying with compressed air. The bonding of substrate and surface was quite well. It could be found some lamellar structure which was typical thermal spraying structure. When enlarge some area, it can be seen small pores formed by molten or partially molten particles in the process of spraying.

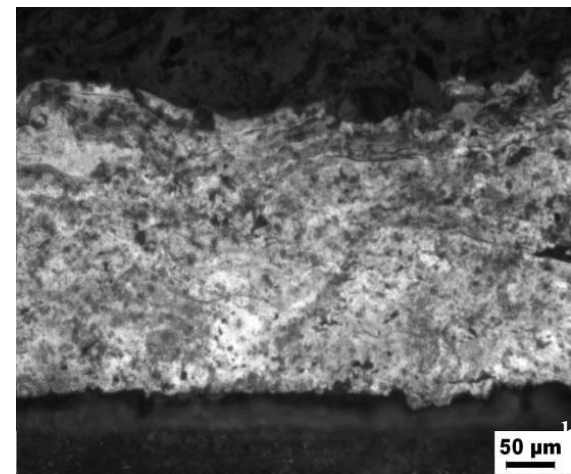

a) Coating and substrate

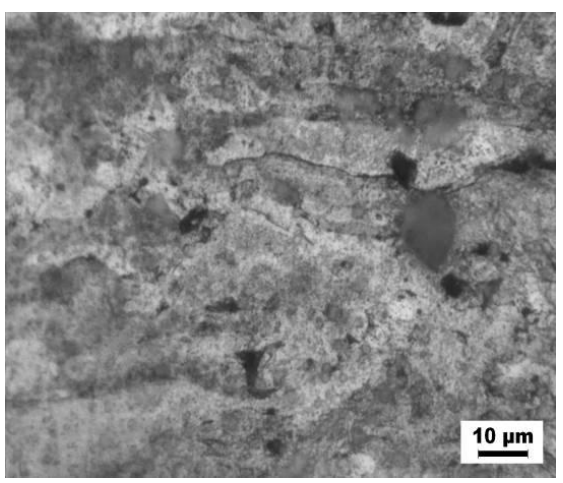

b) Coating

Fig.2 Cross-sectional morphology of $\mathrm{Cu}$ coating deposited by arc spraying with compressed air

\section{Cold spraying coating}

The microstructure of $\mathrm{Cu}$ coating deposited by cold spraying can be seen in Fig.3. The cold spraying coating seemed more dense. It was almost no pores exist.

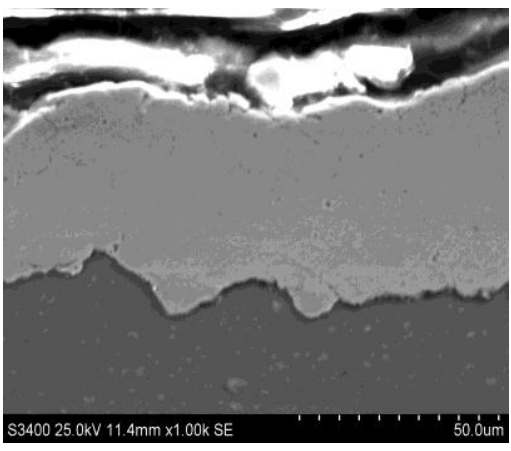

a) Enlarged 1000 times



b) Enlarged 500 times

Fig.3 Cross-sectional morphology of $\mathrm{Cu}$ coating deposited by cold spraying 


\section{Plating Cu coating}

Fig. 4 shows the microstructure of cyanide plating copper coating. The interface between layer and substrate almost has no flaws. The surface of plating $\mathrm{Cu}$ coating has some dispersed cellulation which was quite different from spraying coating, shown in Fig.5.

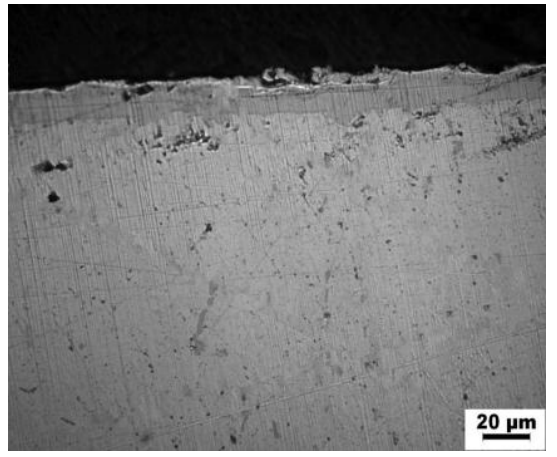

Fig.4 Cross-sectional morphology of $\mathrm{Cu}$ coating deposited by plating

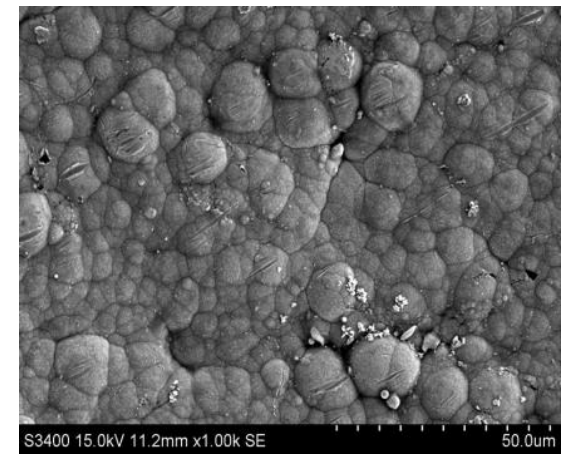

Fig.5 Surface morphology of $\mathrm{Cu}$ coating deposited by plating

\section{X-ray diffraction (XRD) analysis}

Fig.6 shows XRD results respectively by arc spraying, cold spraying and plating coatings. Figure a) is the arc spraying coating under the condition of current $120 \mathrm{~A}$, voltage $30 \mathrm{~V}$ with compressed air. It can be found that there were mainly six peaks in the XRD spectrum and four for $\mathrm{Cu}$, the remaining two peaks was $\mathrm{Cu}_{2} \mathrm{O}$. It can be conclude that the oxidation phenomenon exist in the process of thermal spraying. Figure $\mathrm{b}$ ) is the XRD diagram of cold spraying $\mathrm{Cu}$ coating. It can be seen that it has five peak, the first peak of $\mathrm{Cu}_{2} \mathrm{O}$ is too tiny, almost can be ignored, the other is $\mathrm{Cu}$ peak, which shows that in the process of cold spraying $\mathrm{Cu}$ coating was rarely oxidized. The small peak $\mathrm{Cu}_{2} \mathrm{O}$ may be due to the heating gas process or the oxidation of the original powder. Figure c) is XRD result of plating $\mathrm{Cu}$ coating on the aluminium alloy substrate. Without any $\mathrm{Cu}_{2} \mathrm{O}$, which could explain that no oxidation phenomenon occurred. Because the substrate was too thin, the Al peak can be found in the diagram.
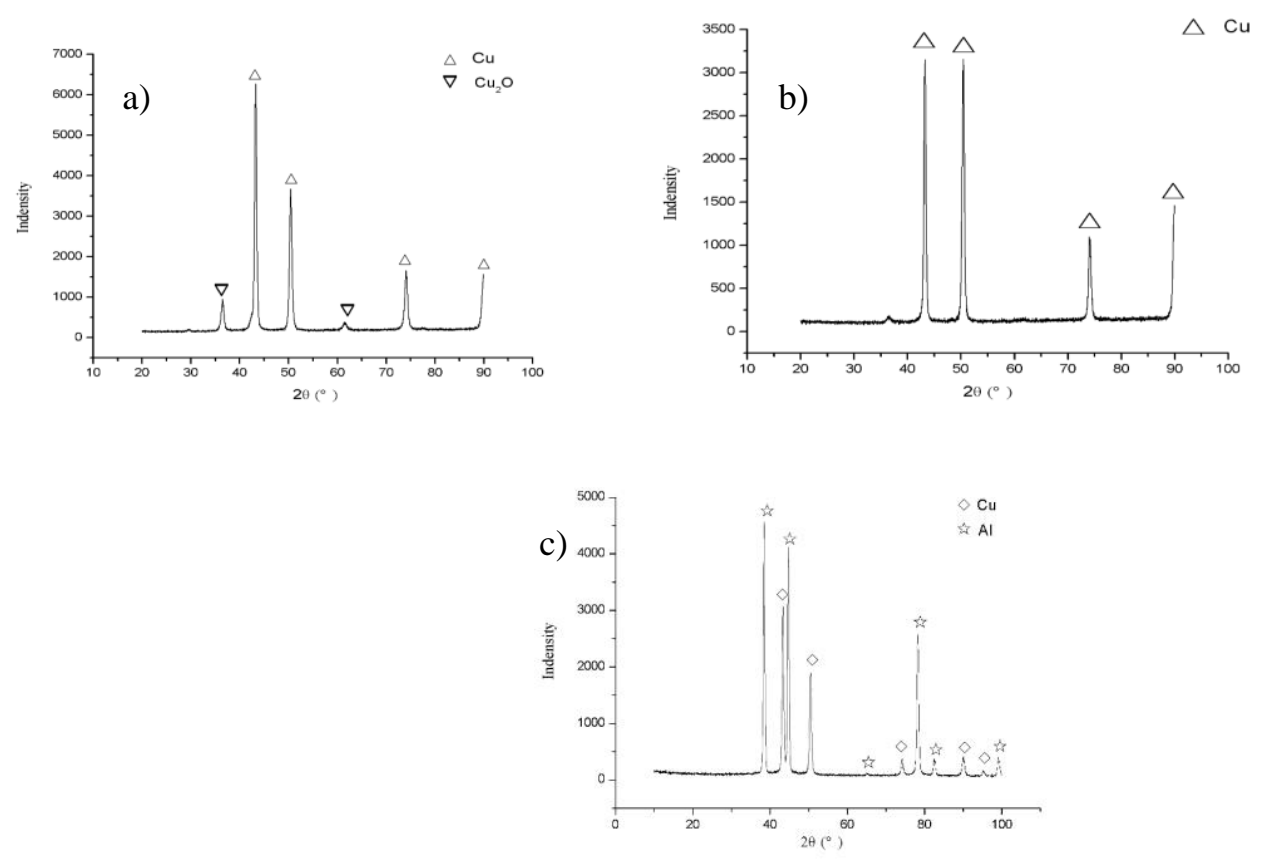
a) Thermal spraying
b) Cold spraying
c) plating

Fig. 6 XRD result using three different methods 


\section{Conclusions}

1) Compared with thermal spraying and plating method to deposit $\mathrm{Cu}$ coating , cold spraying technique is more suitable for coating preparation. There was less oxidation in the coating.

2) Under the protection of $\mathrm{N}_{2}$ or $\mathrm{Ar}$, arc spraying $\mathrm{Cu}$ coating has partial oxidation which was almost ignored.

3) The plating $\mathrm{Cu}$ coating surface presented cellular structure. In the course of practical application, the surface has the problem of easy discoloration caused by oxidation.

\section{Acknowledgement}

This work was financially supported by the Chinese National Natural Science Foundation No. 51301112, The Science Research Program of Education Department in Liaoning Province No L2014048.

\section{References}

[1] J. Wolke, C. Klein, J. de Blieck-Hogervorst, et al, in Proc. the 5th NTSC, 1993.

[2] H. Steffens, M. Dvorak, K. Nassenstein, in : Proc. of the ITSC 1992.

[3] H. Hamatani, N. Shimoda and S. Kitaguchi, Sci. Technol. Adv. Mater, 4 (2003) 197-204.

[4] C. Moreau, J.F. Bisson, R. S. Lima, et al,Pure Appl. Chem., 77 (2005)443-448.

[5] M. Lang, R. Henne, S. Schaperet al, J. Therm. Spray Technol.,10 (2001) 618-624. 